\title{
Functional copper transport explains neurologic sparing in Occipital Horn syndrome
}

Jingrong Tang, $\mathrm{MD}, \mathrm{Ph} \mathrm{D}^{1}$, Stephen Robertson, $M D^{2}$, Kristen E. Lem, $B A^{1}$, Sarah C. Godwin, $B A^{1}$, and Stephen G. Kaler, $M D^{1}$

\begin{abstract}
Objective: A range of neurologic morbidity characterizes childhood-onset copper transport defects, including severe Menkes disease and milder occipital horn syndrome. Both phenotypes are caused by mutations in ATP7A, which encodes a copper-transporting adenosine triphosphatase, although defects causing occipital horn syndrome are rarely reported and nearly always involve exon-skipping (six of eight prior reports). Our objective was to characterize a novel occipital horn syndrome mutation (N1304S) not associated with aberrant splicing and to determine whether functional copper transport was associated with this allele. Methods: We studied two brothers with typical occipital horn syndrome and used yeast complementation and timed growth assays, exploiting a Saccharomyces cerevisiae mutant strain, to assess in vitro N1304S copper transport. Results: We documented that N1304S has approximately 33\% residual copper transport, a result not inconsistent with a similar patient we reported with an exon-skipping mutation whose cells showed correctly spliced mRNA transcripts 36\% of normal. Conclusion: These patients' mild neurologic phenotypes, together with our yeast complementation and growth experiments, imply that N1304S does not completely block copper transport to the developing brain early in life. The findings suggest that neurologic sparing in untreated occipital horn syndrome is associated with approximately 30\% residual functional activity of ATP7A. Genet Med 2006:8(11):711-718.
\end{abstract}

Menkes disease (Online Mendelian Inheritance in Man [OMIM] 309400) and Occipital Horn syndrome (OHS) (OMIM 304150) are allelic X-linked recessive disorders caused by defects in a gene that encodes an evolutionarily conserved copper-transporting adenosine triphosphatase (ATPase) (ATP7A, OMIM 300011). ${ }^{1-4}$

In mammals, this gene product functions as an intracellular pump to transport copper into the trans-Golgi network for incorporation into copper-requiring enzymes, including dopamine- $\beta$ hydroxylase, and mediates copper exodus from cells. ${ }^{5}$ In the small intestine, ATP7A is needed for the passage of copper from duodenal mucosal cells into blood and is expressed in cells that comprise the blood-brain barrier, brain capillary endothelial cells, and astrocytes, ${ }^{6}$ where it is required for delivery of copper to neurons within the central nervous system. In liver, a homologous copper transporter, $A T P 7 B$, excretes copper from hepatocytes into the biliary tract. ${ }^{7}$ Homozygous mutations in this latter gene result in hepatic copper overload and the autosomal recessive condition, Wilson disease. ${ }^{8}$

\footnotetext{
From the ${ }^{1}$ Unit on Pediatric Genetics, Laboratory of Clinical Genetics, National Institute of Child Health and Human Development, National Institutes of Health, Bethesda, Maryland; and ${ }^{2}$ Department of Paediatrics and Child Health, Dunedin School of Medicine, Dunedin, New Zealand.

Stephen G. Kaler, MD, National Institutes of Health Building 10, Room 5-2571, 10 Center Drive MSC 1832, Bethesda, MD 20892-1832.

Submitted for publication May 10, 2006.

Accepted for publication August 10, 2006.

DOI: 10.1097/01.gim.0000245578.94312.1e
}

The disparate neurologic and pathologic phenotypes of Menkes disease and OHS are believed to reflect differential copper delivery to the brain and variable deficiency of enzymes that normally require copper as a cofactor. ${ }^{9}$ In addition to dopamine- $\beta$ hydroxylase, these enzymes include peptidyl-amidating monooxygenase, cytochrome c oxidase, superoxide dismutase, tyrosinase, and lysyl oxidase. In classic severe Menkes disease, affected infants typically appear healthy at birth and advance normally for 2 to 3 months; however, subsequent growth and neurodevelopment are arrested, early milestones (smiling, visual tracking, head control, rolling over) are lost, and seizure activity commonly occurs. ${ }^{9,10}$ Cerebral atrophy and dysmyelination ensue. ${ }^{9}$ Connective tissue abnormalities, ascribed to lysyl oxidase deficiency, also develop, including skin and joint laxity, urinary bladder diverticula, pectus excavatum, gastrointestinal polyps, and generalized vascular tortuosity. ${ }^{9,11}$

OHS may share the connective tissue abnormalities of classic Menkes disease and features the gradual development of distinctive calcifications within the tendons that attach the sternocleidomastoid and trapezius muscles to the occiput, ${ }^{4}$ from which the syndromic name was derived. ${ }^{12,13}$ Because the neurologic phenotype in OHS is mild (dysautonomia including syncope, orthostatic hypotension, and chronic diarrhea), affected individuals often escape detection until mid-childhood or later. ${ }^{4,12-17}$

The molecular basis for typical OHS most often involves exon skipping with reduction of correct mRNA processing compared with normal.4,18-22 Six of eight typical OHS mutations reported, as well as the molecular defect in a mouse 
model of OHS, ${ }^{18}$ involve such aberrant splicing. In two other patients with typical OHS, a deletion in the promoter region ${ }^{23}$ and a frameshift mutation in the final exon ${ }^{24}$ were associated with the phenotype. We and others ${ }^{4,18,21,22}$ have speculated that the molecular defects underlying OHS allow production of some residual copper transport activity; however, functional copper transport was not assessed for any of these mutations, except for radiolabeled copper egress studies in cultured fibroblasts, an assay that does not quantitatively distinguish classic Menkes from mild Menkes or OHS. ${ }^{4}$ In the first patient with typical OHS defined molecularly (S833G, located within the splice donor site of exon 11 and leading to skipping of exons 11 and/or 12 in some transcripts, as well as some properly spliced transcripts), ${ }^{4,25}$ the level of correctly spliced transcripts was estimated as $36 \%$ of normal as measured by RNase protection. ${ }^{4}$ In another patient, ${ }^{21}$ whose clinical picture was described as typical of OHS but who did not achieve independent ambulation until 3 years of age (compared with 1.5 years in the first patient with $\mathrm{OHS}^{4}$ ) or start talking until 3.5 years, a 4-base pair (bp) intronic deletion beginning at the +6 position of the splice donor site for exon 6 was found, resulting in skipping of exon 6 in a majority of transcripts. Quantitative reverse transcriptase polymerase chain reaction (RT-PCR) using this patient's fibroblasts suggested that correctly spliced transcripts were produced at a level only $2 \%$ to $5 \%$ of normal. However, the same mutation, reported in a Japanese patient, showed $18 \%$ to $21 \%$ properly spliced transcripts by quantitative RT-PCR of fibroblast mRNA. This latter patient manifested similar significant developmental delays; he spoke a few words at 32 months of age and walked (with support) at 4 years of age.

The adenosine triphosphate (ATP)-binding domain of Ptype ATPases is highly conserved among cation pumps, ${ }^{1,26}$ connoting the fundamental importance of this motif to the function of these transporters. In addition, characterization of the high-resolution structure of the calcium ATPase from skeletal muscle sarcoplasmic reticulum suggests the importance of the domain in energy transfer to cation sites. ${ }^{27}$ Five missense mutations involving four different residues of this domain in the copper ATPase ATP7A have all been associated with the classic severe Menkes disease phenotype. ${ }^{28}$

We report on two brothers with typical OHS in whom we identified a novel mutation within the ATP-binding domain of ATP7A. Characterization of this defect contributes to our understanding of the relationship between neurologic phenotypes, function of the ATP-binding domain, and residual copper transport in OHS.

\section{MATERIALS AND METHODS}

\section{Patient case histories}

The patients were studied under a protocol approved by the National Institute of Child Health and Human Development Institutional Review Board.

The proband (Fig. 1, A-C) was born to unrelated parents after an uncomplicated pregnancy. The birth weight was 3.77 $\mathrm{kg}$ (50th centile), the length was $52 \mathrm{~cm}$ (50th centile), and the head circumference was $34 \mathrm{~cm}$ (25th centile). At delivery, he sustained bilateral cephalohematomas that slowly resolved over several months. The skin was noted to be hyperelastic and redundant. There were no dysmorphic features noted. The patient had persistent gastroesophageal reflux caused by a hiatal hernia throughout infancy and early childhood.

At 1 year of age, his serum copper level was $8.2 \mu \mathrm{mol} / \mathrm{L}$ (normal range $12-28 \mu \mathrm{mol} / \mathrm{L}$ ) and ceruloplasmin was 170 $\mathrm{mg} / \mathrm{L}$ (normal range $170-560 \mathrm{mg} / \mathrm{L}$ ).

Gross motor milestones were initially delayed, but other areas of neurodevelopment progressed normally. He sat unsupported at 16 months and walked independently at 24 months. Recurrent headaches were noted in early childhood but have since resolved. He had a small number of intermittent, generalized seizures during childhood that did not require anticonvulsant treatment. A computed tomography scan of the head at 4 years of age was normal, as was a magnetic resonance imaging of the head performed at 10 years of age. Presently, he demonstrates above-average performance at school. He has intermittent episodes of dizziness. There are no gastrointestinal problems.

A skeletal survey showed the presence of occipital horns bilaterally at age 4 years (Fig. 2A), short broad clavicles, and broad and flat ilia. The long bones exhibited under-modeling of the metaphyses and broadening of the diaphyses. At age 11 years, a dual-energy $\mathrm{x}$-ray absorptiometry scan demonstrated bone mineral density z scores of -0.4 for the femoral neck and -1.9 for the lumbar spine. Orthopedic complications have included the development of marker bilateral genu valgum deformities requiring bilateral tibial osteotomies at age 13 years. His metacarpophalangeal and interphalangeal joints are hypermobile, and both radial heads remain dislocated (Fig. 1C). He has a nonprogressive combination of exaggerated cervical lordosis, thoracic kyphosis, and lumbar lordosis, without scoliosis. Multiple diverticula of the urinary bladder were noted (two instances of bladder wall rupture occurred), and the ureters became severely dilated as the result of vesicoureteral reflux (Fig. 2C).

The second affected male (Fig. 1, D, E), a full sibling of the proband, was born after an uncomplicated pregnancy. His birth weight $(3720 \mathrm{~g})$, length $(52 \mathrm{~cm})$, and OFC $(35.2 \mathrm{~cm})$ were all normal. He walked independently at 16 months of age, and his overall neurodevelopment has been normal. His skin was noted to be hyperelastic (Fig. 2E), as was his brother's, and hyperextensibility of the small joints of the hands was also noted. Skull radiographs at age 6 years did not demonstrate occipital horns. Ultrasounds of the bladder did not demonstrate bladder diverticula, and the kidneys were normal in size. At age 6 years, he showed genu valgum (Fig. 2B), his height was at the 25 th centile, and his weight was at the 50th centile. His hair was coarse, and he had mild asthma.

The family history is notable for nine full siblings (three males and five females) and two half-siblings, all of whom are healthy. The mother of both boys was diagnosed with unilateral club foot requiring multiple surgeries as a young child. She has no overt neurologic problems, although her hair is coarse 


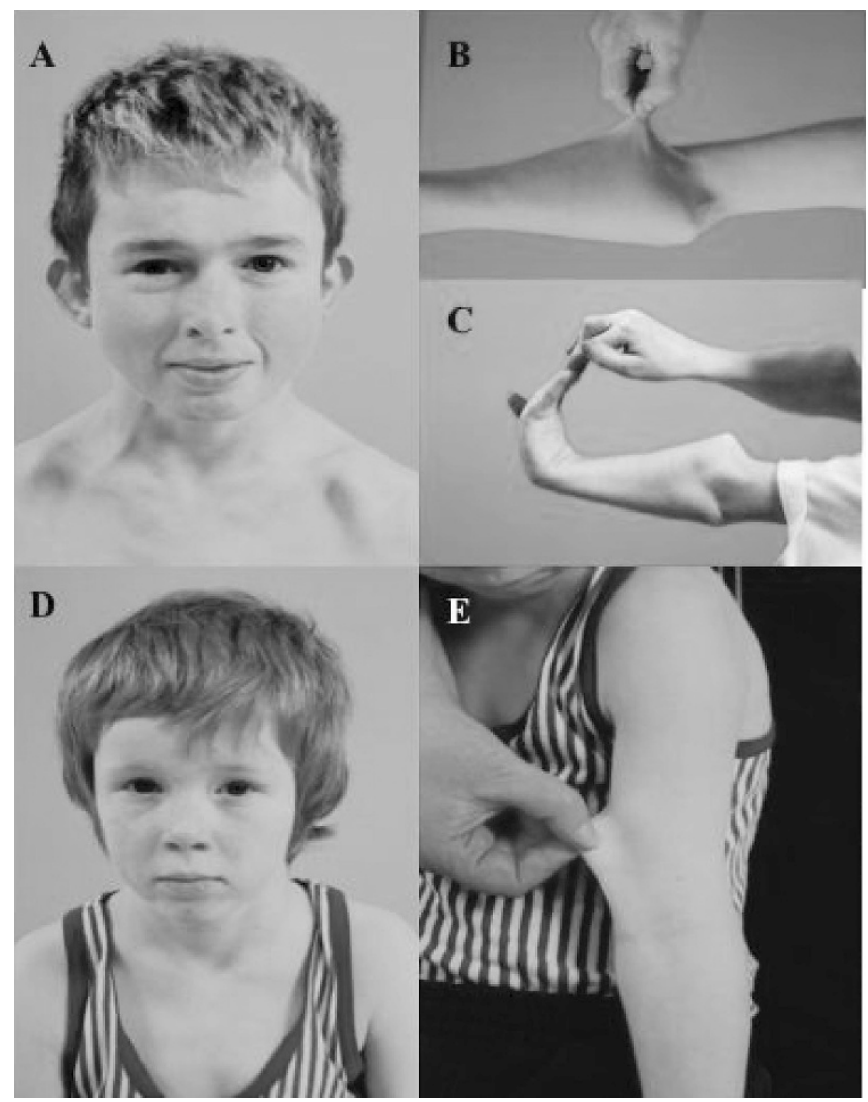

Fig. 1. Clinical phenotype in brothers with OHS. Unremarkable craniofacial appearances (A, D) except for coarse hair. Skin laxity is evident in both (B, E). Metacarpophalangeal joint laxity and elbow dislocations are manifest in the proband $(\mathrm{C})$.

and she has mild hyperextensibility of the metacarpophalangeal and interphalangeal joints.

\section{DNA isolation, mutation analysis, and restriction enzyme digestion}

Genomic DNA was isolated from the patient's peripheral blood using the Wizard Genomic DNA Purification Kit (Promega, Madison, WI) according to the manufacturer's instructions. $\mathrm{Mu}$ tation analysis of the ATP7A gene was carried out as previously described. ${ }^{29}$ To screen genomic DNA from the patients, their mother, and normal controls for an alteration in exon 20, we incubated 10 to $17 \mu \mathrm{L}$ of exon $20 \mathrm{PCR}$ product (332 bp) ${ }^{29}$ with 1 $\mu \mathrm{L}$ of restriction enzyme Tsp45I (New England Biolabs, Ipswich, MA), $2 \mu \mathrm{L}$ of buffer NEB 1 , and 0 to $7 \mu \mathrm{L}$ deionized water overnight at $65^{\circ} \mathrm{C}$. The products of digestion were electrophoresed through a $2 \%$ agarose gel and photographed.

\section{Construction and mutagenesis of the ATP7A cDNA}

The coding region of ATP7A was obtained by digesting MNK-pAdlox (gift of Ann Hubbard, Johns Hopkins University School of Medicine, Baltimore, MD) with XhoI/SpeI, gelpurifying the $4.5-\mathrm{kb}$ fragment generated, and ligating into the yeast integrative expression vector pYes6/CT (Invitrogen, Frederick, MD). The fidelity of the entire MNKpYES6/CT sequence with the normal ATP7A cDNA was verified by auto- mated sequencing (Perkin-Elmer, Wellesley, MA) according to the manufacturer's instruction.

Site-directed mutagenesis to generate the N1304S mutant allele (see bold and italicized primer bases) was performed by a stepwise PCR reaction using oligonucleotide primers M6F 3192-3216 (5' -GTT CTA ACA GCC ATT GGA GAT GGC-3' $)$ / N1304S-R (5' -CCA GAG CTG GGG GAG T $C$ A CTG ATT CCA TC-3') and N1304S-F (5'-GA GAT GGA ATC A $G$ T GAC TCC CCA GCT CTG-3')/CYC-1 (5'-GCG TGA ATG TAA GCG TGA C-3') 5273-5293, pYes6/CT vector. These two PCR products, incorporating the A4056G mutation corresponding to N1304S, were then used as template for amplification of a single 1.485-kb fragment (N1304S-A2). This fragment was then ligated into pPCR2.1 cloning vector (Invitrogen) and transformed to Top10F' Escherichia coli (Invitrogen), and the sequence was verified by restriction digest mapping and automated sequencing. N1304S-A2 was then excised from N1304SA2/pPCR2.1 by digestion with Kpn1/Apa I and replaced the normal ATP7A cassette in MNK-pYes6/CT. The presence of the N1304S mutation was verified by double-stranded automated sequencing. Transcription of sequences cloned into pYES6/CT was mediated by the GAL1 promoter and induced in the presence of galactose and raffinose.

\section{Saccharomyces cerevisiae strain transformation}

Saccharomyces cerevisiae strains BY4743 (wild type) and YDR270W ( $\operatorname{ccc} 2 \Delta$ copper transport deletion $)^{30}$ used in this study were gifts from Alan Hinnebusch, Intramural Research Program, NICHD. Genotypes are as follows: BY4743: MATa/MAT $\alpha$, his $3 \Delta 1 /$ his $3 \Delta 1$, leu $2 \Delta 0 /$ leu $2 \Delta 0$, lys $2 \Delta 0 /+$, met $15 \Delta 0 /+$, ura $3 \Delta 0 /$ $\operatorname{ura} 3 \Delta 0$, fet $3 \Delta$; and YDR270W: MATa/MAT $\alpha$, his $3 \Delta 1 /$ his $3 \Delta 1$, leu2 $\Delta 0 /$ leu2 $\Delta 0$, lys $2 \Delta 0 /+$, met15 $\Delta 0 /+$, ura $3 \Delta 0 /$ ura $3 \Delta 0, \operatorname{ccc} 2 \Delta /$ $\operatorname{ccc} 2 \Delta$. The YDR270W strain was created by the Saccharomyces Genome Deletion Project. ${ }^{31}$ All strains were grown at $30^{\circ} \mathrm{C}$ in complete synthetic media (Bio101) or the appropriate modified medium supplemented with $2 \%$ glucose. Competent yeast cells of ccc $2 \Delta$ were made by using S.c. EasyComp Transformation Kit (Invitrogen), following the manufacturer's instructions. One microgram of DNA of pYES6/CT, MNK pYES6/CT, and N1304S pYES6/CT were added to $50-\mu \mathrm{L}$ aliquots of $\operatorname{ccc} 2 \Delta$-competent cells, incubated at $30^{\circ} \mathrm{C}$ for 1 hour with intermittent vortexing, and streaked onto yeast peptone dextrose (YPD) medium plates containing $75 \mu \mathrm{g} / \mathrm{mL}$ blasticidin (Sigma, St. Louis, MO). Positive clones were mixed with Solution III by vortexing the tubes vigorously every 15 minutes at $30^{\circ} \mathrm{C}$ for 1 hour. After incubation at $30^{\circ} \mathrm{C}$ for 48 to 72 hours, positive clones were identified.

\section{Growth on experimental media}

Copper/iron-limited, iron-sufficient, and copper-sufficient media were prepared from modified synthetic media, as described. ${ }^{32}$ The carbon source was changed, from $2 \%$ glucose to $2 \%$ galactose (Sigma) and $1 \%$ raffinose (Sigma), to allow induction from the pYES6 vector. Copper/iron-limited medium was prepared with yeast nitrogen base (YNB) lacking both $\mathrm{CuSO}_{4}$ and $\mathrm{FeCl}_{3}$ (US Biologicals, Swampscott, MA), to 

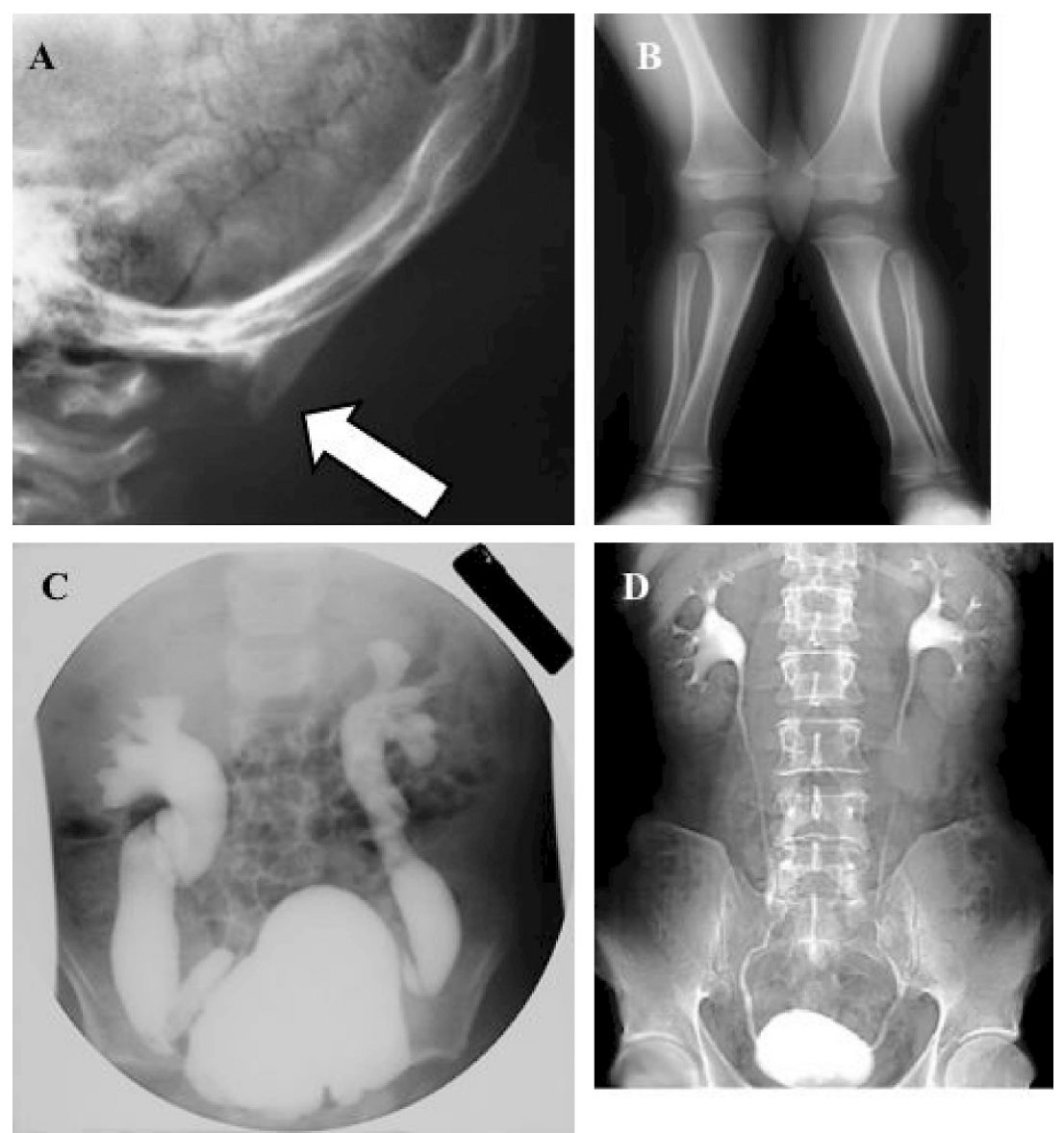

Fig. 2. Radiographic findings in brothers with OHS. Occipital exostoses (A, arrow) and bladder diverticula with grossly dilated ureters (C) in the proband relative to a normal adult cystourethrogram (D). Genu valgum deformity present in younger sibling (B).

which $50 \mathrm{mM}$ MES buffer ( $\mathrm{pH}$ 6.1), $4 \mathrm{mM}$ ferrozine, $10 \mu \mathrm{M}$ $\mathrm{Fe}\left(\mathrm{NH}_{4}\right)_{2}\left(\mathrm{SO}_{4}\right)_{2}$, and $1 \mu \mathrm{M} \mathrm{CuSO} 4$ were added. Copper- and iron-sufficient media were prepared by adding $500 \mu \mathrm{M} \mathrm{CuSO}_{4}$ and $350 \mu \mathrm{M} \mathrm{Fe}\left(\mathrm{NH}_{4}\right)_{2}\left(\mathrm{SO}_{4}\right)_{2}$, respectively, to the copper/ironlimited media.

\section{Yeast complementation assay}

For complementation assays, cells grown to saturation in liquid conventional synthetic medium (YPD) were washed three times with sterile, deionized ice-cold water, resuspended in induction media containing 2\% galactose (Sigma) and $1 \%$ raffinose, and grown at $30^{\circ} \mathrm{C}$ in a shaking incubator (220 rpm) for 16 hours. Cells were harvested, washed, and cultured in copper/iron-limited medium for 16 hours. These cells were collected, washed, and diluted in water to an $\mathrm{A}_{600}$ of 0.1. Tenmicroliter samples were streaked onto agar plates containing media, incubated at $30^{\circ} \mathrm{C}$ for 48 hours, and photographed. Complementation assays for the N1304S mutation were performed in triplicate.

\section{Timed growth assay}

To assess functional copper transport activity as a percentage of normal, $\operatorname{ccc} 2 \Delta$ strains transformed with mutant and wild-type human ATP7A mock-transformed and nontrans- formed $\operatorname{ccc} 2 \Delta$ were grown overnight in copper/iron-limited media and diluted in the same to an $\mathrm{A}_{600}$ of 0.1 in triplicate 10 -mL cultures. Aliquots $(800 \mu \mathrm{L})$ were withdrawn after 2,4 , and 6 hours of growth at $30^{\circ} \mathrm{C}$. To adjust for background, the mean of triplicate $\mathrm{A}_{600}$ readings for $\operatorname{ccc} 2 \Delta$ was subtracted from those of the mutant and wild-type transformed strains at each time point. Growth in copper/iron-limited media for the N1304S mutant allele-transformed strain was assessed at each time point by comparison of N1304S growth and wild-type growth $\left(A_{600}\right.$ mutant $/ A_{600}$ wild-type $\left.\times 100\right)$. The mean value at 2, 4, and 6 hours was calculated as an estimate of functional copper transport activity mediated by N1304S.

\section{RESULTS}

\section{Mutation analysis}

In both brothers and their mother, we detected an A to $G$ transition at nucleotide 4056 in exon 20 of the ATP7A gene (Fig. 3). This alteration changes the translational reading frame from AAU to ACU, predicting the substitution of serine for asparagine at amino acid residue 1304 (N1304S) in exon 20. N1304 is a highly conserved residue in cation-transporting ATPases (Table 1). The mutation creates a novel Tsp45I restriction site that allowed for convenient screening of 50 nor- 


\section{GGAATCAATGACTCCCCAG}
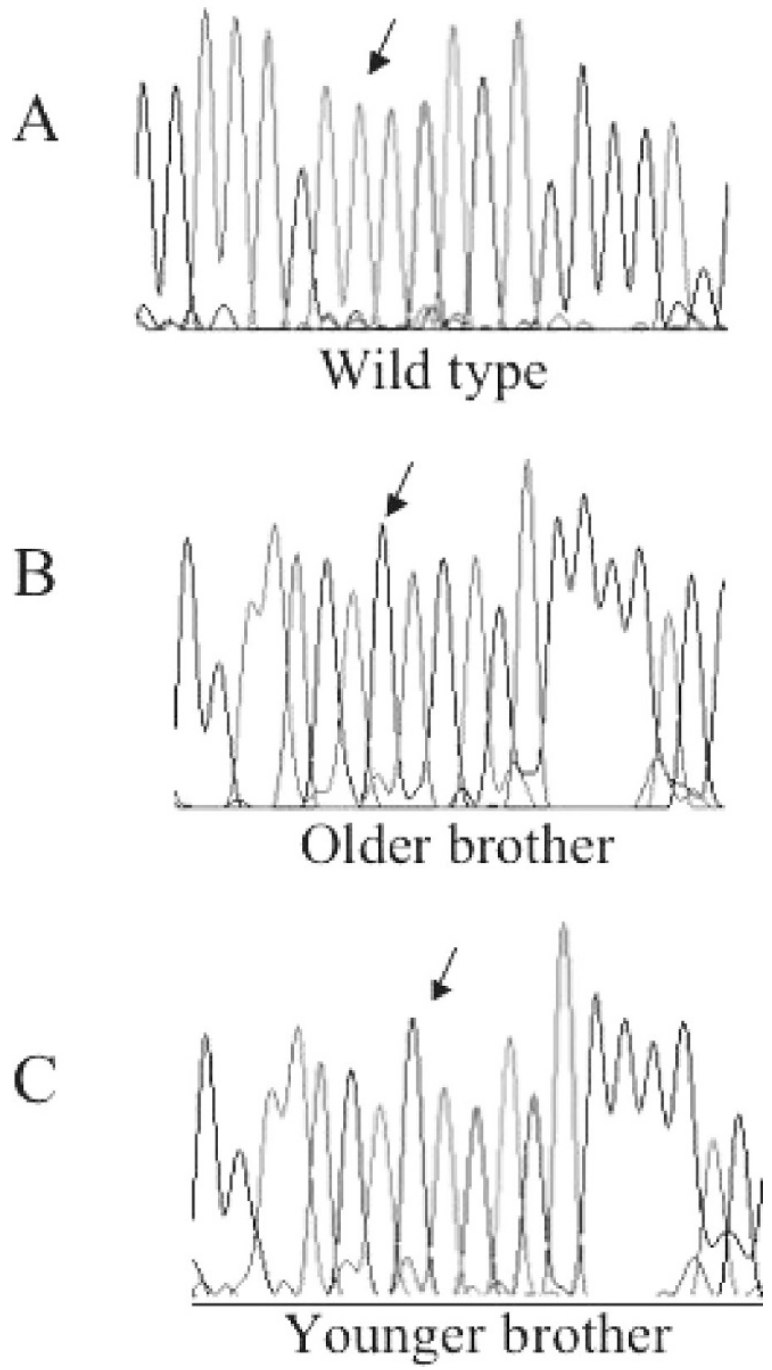

Fig. 3. Sequence analysis reveals N1304S mutation in both siblings. An A to G transition at nucleotide 4056 (asterisk) in exon 20 of the Menkes/OHS gene (ATP7A) changes the translational reading frame from $\mathrm{AAU}(\mathrm{A})$ to $\mathrm{ACU}(\mathrm{B}, \mathrm{C})$, predicting substitution of serine for asparagine at amino acid residue 1304 (N1304S).

mal control chromosomes by digestion of exon 20 amplicons; none showed the new Tsp45I restriction site (data not shown). Digest mapping of the patient's mother's exon 20 revealed both normal and mutant fragments. Because the center of exon 20 contains the sequence (VGDGINDSPALAM) encoding the entire ATP-binding domain, exon skipping during mRNA processing would produce a protein product completely lacking this critical domain and would be incompatible with functional cation transport. ${ }^{26}$

\section{Yeast complementation assay}

The gene CCC2 is the yeast homolog of the Menkes/OHS and Wilson disease genes and is part of the pathway required for highaffinity iron uptake in this organism. ${ }^{30,33}$ The copper-iron con-
Table 1

Conservation of asparagine $(\mathrm{N})$ residue in the ATP-binding domains of ionmotive ATPases

\begin{tabular}{|c|c|}
\hline ATP-binding domain & Ion-motive ATPase \\
\hline VGDG I $\underline{\mathbf{N}}$ DSPALAM & ATP7A (Menkes/OHS) \\
\hline VGDGV $\underline{\mathbf{N}}$ DSPALAQ & ATP7B (Wilson disease) \\
\hline TGDGV $\underline{\mathbf{N}}$ DSPALKK & $\mathrm{Na}^{+} / \mathrm{K}^{+}$ATPase (human) \\
\hline TGDGV $\underline{\mathbf{N}}$ DAPALKK & $\mathrm{Ca}^{++}$ATPase (SERCA1) \\
\hline VGDGI N DAPALAL & CCC2 (S. cerevisiae) \\
\hline
\end{tabular}

ATP, adenosine triphosphate; ATPase, adenosine triphosphatase; OHS, occipital horn syndrome.

nection in yeast relates to the fact that iron uptake is controlled by a copper-dependent ferroxidase, called Fet $3 \mathrm{p} .{ }^{34}$ In the S. cerevisiae mutant lacking $C C C 2(\operatorname{ccc} 2 \Delta)$, Fet3p activity is absent and no growth occurs on copper/iron-limited media. ${ }^{32}$ However, transformation of $\operatorname{ccc} 2 \Delta$ with a wild-type copper transport cDNA or with a mutant copper transport allele with some residual activity can partially restore Fet3p activity and allow growth under copper/iron-limited conditions. ${ }^{32,35-38}$

We first documented that the four strains, nontransformed $\operatorname{ccc} 2 \Delta, \operatorname{ccc} 2 \Delta$ mock-transformed with an empty vector, $\operatorname{ccc} 2 \Delta$ transformed with the normal ATP7A allele, and ccc $2 \Delta$ transformed with the N1304S mutant allele, all grew on YNB media supplemented with copper (Fig. 4B) or iron (Fig. 4C), as well as on YPD media (Fig. 4D). As expected, on copper/iron-limited media, both nontransformed $\operatorname{ccc} 2 \Delta$ and mock-transformed $\operatorname{ccc} 2 \Delta$ failed to grow (Fig. 4E, quadrants 1 and 2, respectively). In contrast, transformation of $\operatorname{ccc} 2 \Delta$ with the normal $A T P 7 A$ allele (Fig. 4E, quadrant 3) or the mutant N1304S allele (Fig. $4 \mathrm{E}$, quadrant 4) restored growth. This result demonstrated complementation of the $\operatorname{ccc} 2 \Delta$ copper transport defect by both alleles (integrative plasmids), although growth appeared lighter for the N1304S mutant transfectant compared with the wild type.

\section{Growth assay to quantitate estimated residual activity}

To estimate the amount of residual copper transport activity retained by the mutant $\mathrm{N} 1304 \mathrm{~S}$ allele, we designed a rapid and reproducible yeast growth assay using copper/iron-limited liquid media. Over a 6-hour time course, growth of the untransformed $\operatorname{ccc} 2 \Delta$ strain was compared with that of $\operatorname{ccc} 2 \Delta$ transformed with the normal ATP7A or the N1304S mutant allele (Fig. 5). The $\operatorname{ccc} 2 \Delta / \mathrm{N} 1304 \mathrm{~S}$ construct was associated with a growth rate approximately $33 \%$ of $\operatorname{ccc} 2 \Delta$ /wild-type ATP7A.

\section{DISCUSSION}

Irrespective of their cation specificities, ion-motive ATPases all have highly conserved ATP-binding regions (Table 1), including the asparagine residue mutated in the brothers reported here whose mild clinical phenotypes are consistent with typical OHS. This specific asparagine residue is believed to have a critical role in mediating the transition from an E1 to E2 

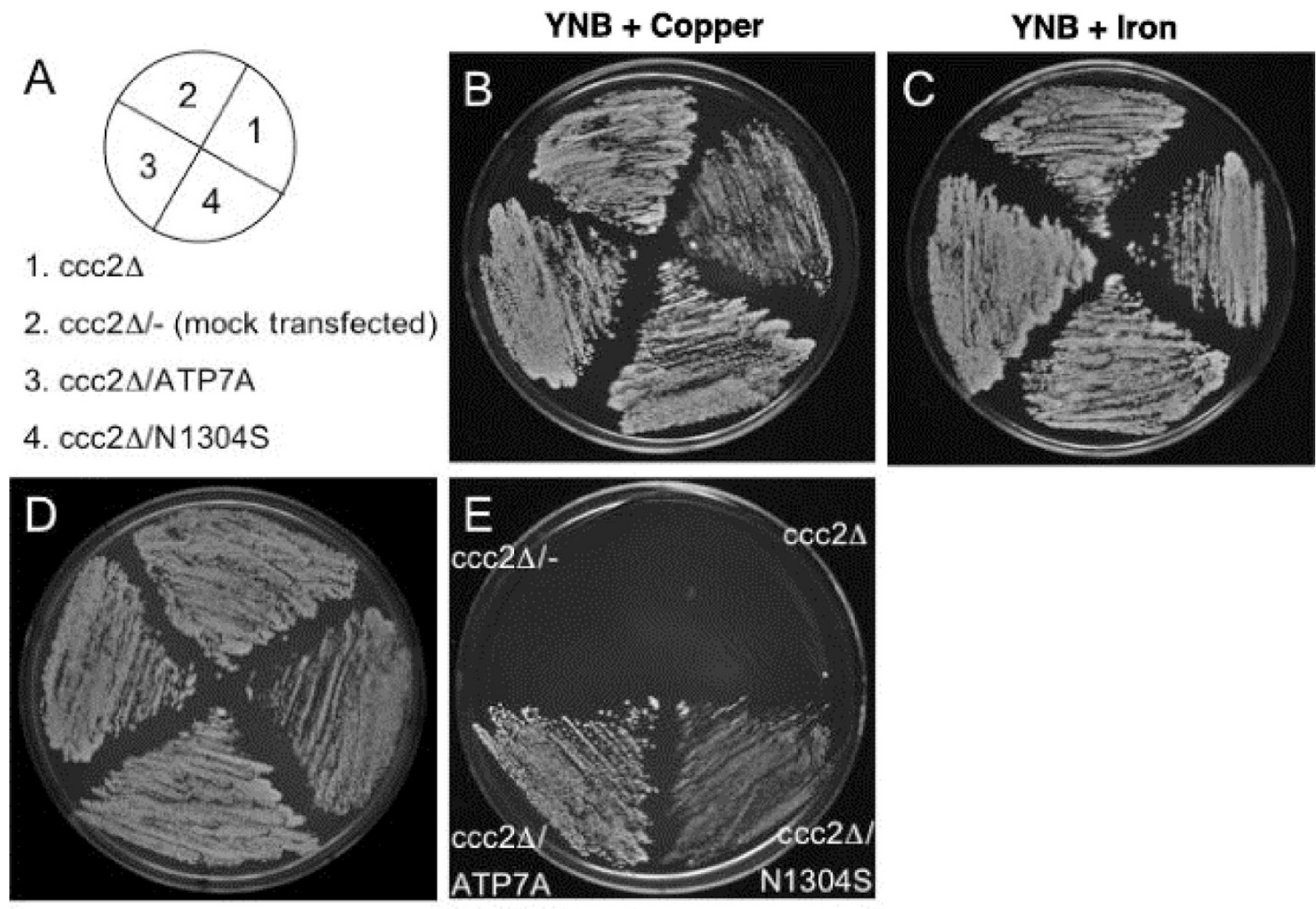

YPD

\section{Copper//ron-Limited YNB}

Fig. 4. N1304S mutant allele complements $\operatorname{ccc} 2 \Delta$ S. cerevisiae copper transport defect. CCC2 is the yeast homolog of the Menkes/OHS and Wilson disease genes and is critical in the pathway for high-affinity iron uptake in this organism. Iron uptake in S. cerevisiae is controlled by the copper-dependent ferroxidase Fet3p. CCC2 normally delivers copper to Fet3p. In the S. cerevisiae mutant lacking CCC2 (ccc2 $\Delta$ ), Fet3p activity is absent and growth on copper/iron-limited media cannot occur (E, quadrant 1). Transformation of ccc2 $\Delta$ with the normal ATP7A allele restores Fet3 activity, allowing growth under the copper/iron-limited conditions (E, third quadrant). The ccc2 $\Delta$ copper transport mutant, ccc2 $\Delta$ mock-transformed with an empty vector, $\operatorname{ccc} 2 \Delta$ transformed with the wild-type ATP7A allele, and ccc2 $\Delta$ transformed with the N1304S mutant allele all grow on synthetic YNB media supplemented with copper (B) or iron (C) and on YPD media (D). However, on copper/iron-limited YNB media, nontransformed and mock-transformed ccc2 $\Delta$ strains fail to grow (E, quadrants 1 and 2, respectively), whereas transformation of $\operatorname{ccc} 2 \Delta$ with the normal ATP7A allele (E, quadrant 3) or the mutant N1304S allele (E, quadrant 4) restores growth, demonstrating complementation of the ccc2 $\Delta$ copper transport defect. Note lighter growth in quadrant 4. YNB, yeast nitrogen base; YPD, yeast peptone dextrose.

energy state between the ATP-binding and phosphorylation domains of these molecules. ${ }^{26}$ In studies of the Na,K-ATPase, mutation of the equivalent asparagine residue to glutamine (N713Q) did not impair ATP-binding but reduced $\mathrm{Na}, \mathrm{K}-$ ATPase activity in a yeast expression system to between $11 \%$ and $27 \%$ compared with wild type. ${ }^{26}$ These findings are consistent with our findings of significant residual copper transport activity by the N1304S allele in the yeast complementation assay. In both these instances, the amino acid substitution involves replacement of one polar residue by a different polar amino acid. In contrast, another missense alteration affecting N1304 in the Menkes copper ATPase, N1304K, was associated with the classic Menkes disease phenotype. ${ }^{28}$ The N1304K allele likely provides minimal functional residual copper transport because of substitution of a positively charged basic amino acid at this position, which represents a significant biochemical alteration. Several other missense mutations have been noted in the ATP-binding region of ATP7A, including G1300E, G1302R, G1302V, and D1305A, all of which were associated with the classic Menkes disease phenotype. ${ }^{28}$

Quantitation of the amount of correctly spliced stable mRNA in another patient with typical OHS and a neutral amino acid substitution (S833G) at a splice junction was found by RNAse protection to be $36 \% .^{4}$ Because of the nature of the two mutations, it is not possible to use the same assay to compare functional copper transport activity between that mutant allele and N1304S. However, those results are not inconsistent with our estimate of residual copper transport activity determined by yeast complementation studies with $\operatorname{ccc} 2 \Delta$. All three patients with typical OHS (the previous report ${ }^{4}$ and the two brothers reported here) shared similar early neurodevelopmental courses, including walking independently between 16 and 24 months of age. Only one received copper replacement treatment, and it was not early (began at 8 years of age). ${ }^{4}$ These 


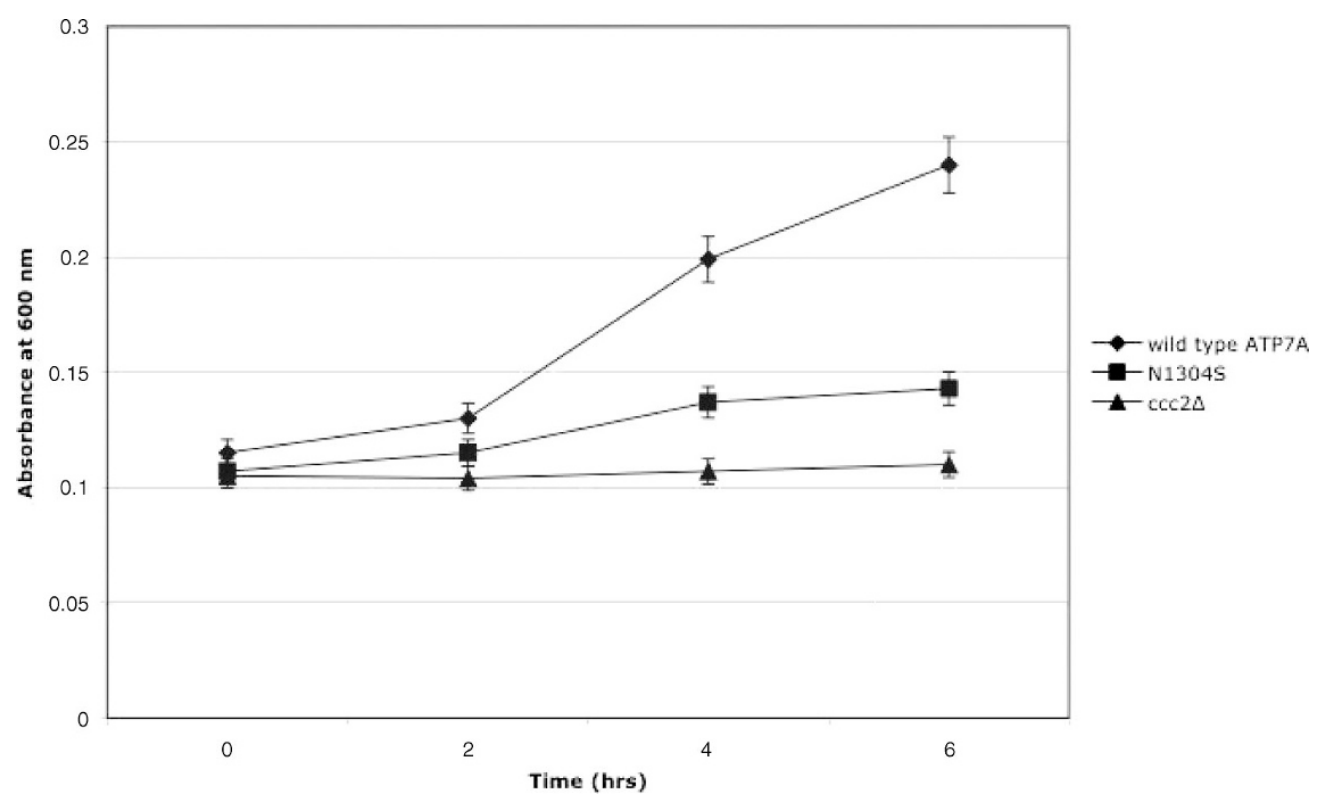

Fig. 5. Evidence of residual copper transport by N1304S mutant allele. Mean percent growth (three time points) in copper/iron-limited media of ccc2 $\Delta$ transformed with N1304S compared with $\operatorname{ccc} 2 \Delta$ transformed with wild-type ATP7A was $33 \%$. The nontransformed $\operatorname{ccc} 2 \Delta$ strain failed to grow.

patients' mild neurologic problems, even without early copper replacement therapy, connote successful copper delivery across the blood-brain barrier during infancy. A leaky ATP7A splice junction mutation in the first patient ${ }^{4}$ and the documented capacity of the N1304S allele for residual copper transport in the two boys reported here support this conclusion.

Functional residual activity in ATP7A mutant alleles has not been measured in other patients with typical OHS reported to date, including two patients with amino acid substitutions, Q924R and A1325V, who were reported to manifest the OHS phenotype but about whom the clinical neurologic information provided was sparse. ${ }^{28,39} \mathrm{In}$ fact, for the $\mathrm{A} 1325 \mathrm{~V}$ mutation, two other affected males in the family showed a classic Menkes phenotype. ${ }^{40}$ Three well-described patients with exon-skipping mutations ${ }^{18,19}$ had evidence of some concomitant normal splicing that was not quantitated, however, and correlation with neurologic phenotype was not possible. One of the patients was described as neurologically normal at age 14 years, ${ }^{18}$ and another walked independently at 18 months. ${ }^{19}$ It was not clear whether the third patient had ever walked independently, although he was wheelchair-bound by age 15 years. ${ }^{18}$

Another patient, whose neurologic phenotype was described as typical of OHS, but who did not achieve independent ambulation until 3 years of age or begin speaking until 3.5 years, had a 4-bp intronic deletion beginning at the +6 position in the splice donor site of exon 6, resulting in skipping of exon 6 in a majority of transcripts. ${ }^{21}$ Quantitative RT-PCR using mRNA from this patient's fibroblasts suggested that correctly spliced transcripts were produced at a level $2 \%$ to $5 \%$ of normal. However, the identical mutation was reported in another patient with OHS, in whom quantitative RT-PCR of fibroblast mRNA showed $18 \%$ to $21 \%$ properly spliced transcripts compared with normal. ${ }^{22}$ On the basis of these patients' neurologic phenotypes (each achieved inde- pendent walking between 3 and 4 years of age without early copper treatment) relative to classic Menkes disease, we suggest that the latter assessment is a more accurate prediction of residual copper transporter in vivo.

This work represents an initial attempt to draw quantitative correlations between the amount of residual ATP7A copper transport function and clinical phenotype. There is likely a spectrum of clinical effects in patients with mutation at this locus that relates directly to the amount of residual copper transport available to support copper delivery to the brain in the first years of life. The fact that $20 \%$ of residual activity in a gene product can be associated with significant clinical impairment denotes the critical physiologic role of ATP7A in normal neurodevelopment. The effect of residual activity in a transport protein such as ATP7A is distinct from that for residual activity of an enzyme that metabolizes a certain substrate, because copper availability to the brain is not only dependent on ATP7A-mediated flux across the blood-brain barrier but also on transport by the same protein from the gastrointestinal tract into the circulation. Thus, in patients with $20 \%$ residual ATP7A activity, the amount of copper delivered to the brain would actually be on the order of $4 \%$ of normal (i.e., $20 \%$ of $20 \%)$. In contrast, patients with OHS, such as those we describe here, may achieve net copper transport to brain approximately $11 \%$ of normal (i.e., $0.33 \%$ ), ${ }^{2}$ approximately threefold more efficient. We hypothesize that this paradigm is also relevant in determining clinical outcomes in response to early copper treatment of classic Menkes disease. With normalization of blood copper levels through early subcutaneous copper injection treatment, we speculate that at least $10 \%$ residual ATP7A transport activity is needed for brain copper delivery sufficient for successful neurodevelopmental outcomes in such patients. 
Female heterozygous for ATP7A mutations rarely manifest overt clinical or biochemical abnormalities..$^{9}$ If $30 \%$ to $35 \%$ residual activity produces the typical OHS phenotype, some female carriers might be expected to have symptoms attributable to random X-chromosome inactivation. ${ }^{41}$ However, no female patients with OHS have been reported to date. It is known that X-inactivation occurs at different times in different tissues ${ }^{40}$ and increases with age, ${ }^{41}$ factors that could complicate the ascertainment of such individuals. It is also possible that mosaicism and cell-specific effects in astrocytes, brain capillaries, or neurons may contribute to phenotypic differences based on gender.

In summary, we identified two brothers with typical OHS and found the first missense mutation not associated with aberrant splicing as the cause of this phenotype. We characterized the mutation (N1304S) in a yeast complementation assay that indicated its capacity for approximately $33 \%$ residual copper transport activity. Separate evidence from studies of the Na,KATPase indicate that, although this asparagine residue is highly conserved, mutation at the position does not entirely abrogate ion transport. Our findings extend knowledge about structure-function relationships for the ATP-binding region of ATP7A, as well as quantitative correlations between neurologic phenotype and copper delivery to the developing brain.

\section{References}

1. Vulpe C, Levinson B, Whitney S, Packman S, et al. Isolation of a candidate gene for Menkes disease and evidence that it encodes a copper-transporting ATPase. Nat Genet 1993;3:7-13.

2. Chelly J, Tumer Z, Tonnesen T, Petterson A, et al. Isolation of a candidate gene for Menkes disease that encodes a potential heavy metal binding protein. Nat Genet 1993;3:14-19.

3. Mercer JFB, Livingston J, Hall B, Paynter JA, et al. Isolation of a partial candidate gene for Menkes disease by positional cloning. Nat Genet 1993;3:20-25.

4. Kaler SG, Gallo LK, Proud VK, Percy AK, et al. Occipital horn syndrome and a mild Menkes phenotype associated with splice site mutations at the MNK locus. Nat Genet 1994;8:195-202.

5. Cullota V, Gitlin JD. Disorders of copper transport. In: Scriver CR, Beaudet AL, Sly WS, Valle D, editors. The metabolic and molecular bases of inherited disease. New York: McGraw-Hill, 2001:3105-3126.

6. Kaler SG, Schwartz JP. Expression of the Menkes disease homolog in rodent neuroglial cells. Neurosci Res Commun 1998;23:61-66.

7. Roelofsen H, Wolters H, Van Luyn MJ, Miura N, et al. Copper-induced apical trafficking of ATP7B in polarized hepatoma cells provides a mechanism for biliary copper excretion. Gastroenterology 2000;119:782-793.

8. Bull PC, Thomas GR, Rommens JM, Forbes JR, et al. The Wilson disease gene is a putative copper transporting P-type ATPase similar to the Menkes gene. Nat Genet 1993;5:327-337.

9. Kaler SG. Menkes disease. Adv Pediatr 1994;41:263-304.

10. White SR, Reese K, Sato S, Kaler SG, et al. Spectrum of EEG findings in Menkes disease. Electroenceph Clin Neurophysiol 1993;87:57-61.

11. Kaler SG, Westman JA, Bernes SM, Elsayed AM, et al. Gastrointestinal hemorrhage associated with gastric polyps in Menkes disease. J Pediatr 1993;122:93-95.

12. Lazoff SG, Rybak JJ, Parker BR, Luzzatti L, et al. Skeletal dysplasia, occipital horns, diarrhea and obstructive uropathy- a new hereditary syndrome. Birth Defects Orig Artic Ser 1975;11:71-74

13. Sartoris DJ, Resnick D. The horn: a pathognomonic feature of paediatric bone dysplasias. Aust Paediatr J 1987;23:347-349.

14. Byers PH, Siegel RC, Holbrook KA, Narayanan AS, et al. X-linked cutis laxa. Defective cross-link formation in collagen due to decreased lysyl oxidase activity. $N$ Engl J Med 1980;303:61-65.

15. Kuivaniemi H, Peltonen L, Palotie A, Horn N, et al. Abnormal copper metabolism and deficient lysyl oxidase activity in a heritable connective tissue disorder. J Clin Invest 1982;69:730-733.
16. Sartoris DJ, Luzzatti L, Weaver DD, Macfarlane JD, et al. Type IX Ehlers-Danlos syndrome: a new variant with pathognomonic radiographic features. Radiology 1984;152:665-670.

17. Tsukahara M, Imaizumi K, Kawai S, Kajii T, et al. Occipital horn syndrome: report of a case and review of the literature. Clin Genet 1994;45:32-45.

18. Das S, Levinson B, Vulpe C, Whitney S, et al. Similar splicing mutations of the Menkes/mottled copper-transporting ATPase gene in occipital horn syndrome and the blotchy mouse. Am J Hum Genet 1995;56:570-576.

19. Ronce N, Moizard M-P, Robb L, Toutain A, et al. A C2055T transition in exon 8 of the ATP7A gene is associated with exon skipping in an occipital horn syndrome family. Am J Hum Genet 1997;61:233-238.

20. Qi M, Byers PH. Constitutive skipping of alternatively spliced exon 10 in the ATP7A gene abolishes Golgi localization of the Menkes protein and produces the occipital horn syndrome. Hum Mol Genet 1998;7:465-469.

21. Moller LB, Tumer Z, Lund C, Petersen C, et al. Similar splice-site mutations of the ATP7A gene lead to different phenotypes: classical Menkes disease or occipital horn syndrome. Am J Hum Genet 2000;66:1211-1220.

22. Gu YH, Kodama H, Murata Y, Mochizuki D, et al. ATP7A gene mutations in 16 patients with Menkes disease and a patient with occipital horn syndrome. Am J Med Genet 2001;99:217-222.

23. Levinson B, Conant R, Schnur R, Das S, et al. A repeated element in the regulatory region of the MNK gene and its deletion in a patient with occipital horn syndrome. Hum Mol Genet 1996;5:1737-1742.

24. Dagenais SL, Adam AN, Innis JW, Glover TW, et al. A novel frameshift mutation in exon 23 of ATP7A (MNK) results in occipital horn syndrome and not in Menkes disease. Am J Hum Genet 2001;69:420-427.

25. Dierick HA, Ambrosini L, Spencer J, Glover TW, et al. Molecular structure of the Menkes disease gene (ATP7A). Genomics 1995;28:462-469.

26. Pederson PA, Jorgensen JR, Jorgensen PL. Importance of conserved a-subunit segment 709GDGVND for Mg + binding, phosphorylation, and energy transduction in Na,K-ATPase. J Biol Chem 2000;275:37588-37595.

27. Toyoshima C, Nakasako M, Nomura H, Ogawa H, et al. Crystal structure of the calcium pump of sarcoplasmic reticulum at 2.6 A resolution. Nature 2000;405:647655.

28. Moller LB, Bukrinsky JT, Molgaard A, Paulsen M, et al. Identification and analysis of 21 novel disease-causing amino acid substitutions in the conserved part of ATP7A. Hum Mutat 2005;26:84-93.

29. Liu P-C, McAndrew PE, Kaler SG. Rapid and robust screening of the Menkes disease/occipital horn syndrome gene. Genet Test 2002;6:255-260.

30. Fu D, Beeler TJ, Dunn TM. Sequence, mapping and disruption of CCC2, a gene that cross-complements the $\mathrm{Ca}(2+)$-sensitive phenotype of csgl mutants and encodes a P-type ATPase belonging to the $\mathrm{Cu}(2+)$-ATPase subfamily. Yeast 1995;11:283-292.

31. Winzeler EA, Shoemaker DD, Astromoff AH, Liang H, et al. Functional characterization of the S. cerevisiae genome by gene deletion and parallel analysis. Science 1999;285:901-906.

32. Southron JL, Basu U, Taylor GJ. Complementation of Saccharomyces cerevisiae ccc2 mutant by a putative P1B-ATPase from Brassica napus supports a coppertransporting function. FEBS Lett 2004;566:218-222.

33. Askwith C, Eide D, Van Ho A, Bernard PS, et al. The FET3 gene of S. cerevisiae encodes a multicopper oxidase required for ferrous iron uptake. Cell 1994;76:403410.

34. Yuan DS, Stearman R, Dancis A, Dunn T, et al. The Menkes/Wilson disease gene homologue in yeast provides copper to a ceruloplasmin-like oxidase required for iron uptake. Proc Natl Acad Sci U S A 1995;92:2632-2636.

35. Hung IH, Suzuki M, Yamaguchi Y, Yuan DS, et al. Biochemical characterization of the Wilson disease protein and functional expression in the yeast Saccharomyces cerevisiae. J Biol Chem 1997;272:21461-21466.

36. Payne AS, Gitlin JD. Functional expression of the Menkes disease protein reveals common biochemical mechanisms among the copper-transporting p-type ATPases. J Biol Chem 1998;273:3765-3770.

37. Sambongi Y, Wakabayashi T, Yoshimizu T, Omote H, et al. Caenorhabditis elegans cDNA for a Menkes/Wilson disease gene homologue and its function in a yeast CCC2 gene deletion mutant. J Biochem (Tokyo) 1997;121:1169-1175.

38. Forbes JR, Cox DW. Functional characterization of missense mutations in $A T P 7 B$ Wilson disease mutation or normal variant? Am J Hum Genet 1998;63:1663-1674.

39. Borm B, Moller LB, Hausser I, Emeis M, et al. Variable clinical expression of an identical mutation in the ATP7A gene for Menkes disease/occipital horn syndrome in three affected males in a single family. J Pediatr 2004;145:119-121.

40. Kristiansen M, Knudsen GP, Tanner SM, McEntagart M, et al. X-inactivation patterns in carriers of X-linked myotubular myopathy. Neuromuscul Disord 2003;13: $468-471$.

41. Hatakeyama C, Anderson CL, Beever CL, Penaherrera MS, et al. The dynamics of $\mathrm{X}$-inactivation skewing as women age. Clin Genet 2004;66:327-332. 